\title{
Dialogando sobre o conceito de determinação social
}

\author{
A dialogue on the concept of social \\ determination
}

Diálogo sobre el concepto de determinación social

Maria Cecília de Souza Minayo 1

doi: 10.1590/0102-311X00254221

Sinto-me privilegiada pelo fato de que CSP dedique algumas de suas páginas para revisitar fundamentos conceituais muito usados na área a partir de um texto meu 1 . Agradeço à Áurea, ao Jaime e ao Naomar, que dedicaram parte de seu tempo para enriquecer este debate.

Primeiramente, agradeço a participação da querida Áurea Ianni, cientista social da área da saúde cuja obra Mudanças Sociais Contemporâneas e Saúde 2 eu tive a oportunidade de ler após lhe enviar o primeiro rascunho deste artigo, que coincide plenamente quanto aos aspectos tratados na obra. Seu livro e o segundo comentário que Áurea faz do artigo não só o valorizam, como também lhe acrescentam substância e conteúdo. A meu favor, cito dela a seguinte frase: "[a autora ressalta] ...consistente esforço interdisciplinar que a Saúde Coletiva e a Medicina Social latino-americanas desenvolveram com o intuito de problematizar o objeto saúde, esforço de (re)conceituação epistêmica, teórica e sociopolítica, em consonância às condições objetivas da época, e que expressaram o contexto histórico-social e em saúde tanto no âmbito do conhecimento quanto no da ação prática, social e política" 3 (p. 1). Diz Ianni 3 (p. 1) no entanto, que esse "exercício em muito abandonado posteriormente, numa acomodação à repetição, à reificação". E encerra: "o ensaio é muito fiel à trajetória intelectual da autora, ao diálogo epistemológico e teórico em torno da interdisciplinaridade da saúde. É, pois, nesta perspectiva que ela apresenta um leque de questões que auxiliam compreender o campo da Saúde Coletiva e alguns de seus impasses atuais” 3 (p. 1). Áurea querida, me perdoe, mas eu tive que repetir o que você disse, porque eu não teria como expressar melhor as suas palavras!

Quero também agradecer aos meus colegas Jaime Breilh e Naomar Almeida-Filho, ainda que meu ensaio tenha merecido as saraivadas de críticas de Jaime ${ }^{4}$ e tenha sido desmerecido por Naomar 5 como falacioso e "libelo desconstrutivo". Fico imaginando que força teria este texto, que nada mais fez do que discutir um conceito! Em que pontos tão sensíveis teria ele tocado a ponto de desencadear tamanha fúria! O foco do meu texto foi evidenciar que as imensas e incomensuráveis transformações que vivenciamos hoje precisam de novas teorias interpretativas da sociedade, do mundo e, obviamente, da área de Saúde Coletiva, tão vibrante e tão presente academicamente. Se as minhas provocações foram pobres e falaciosas, como diz Naomar 5 , que se convoquem os que se julgam grandes pensadores do campo e que estes busquem outras referências e protagonizem mudanças.

A bem da verdade, informo que há anos questiono o uso do conceito de determinação social como histórico 6, e o faço, dentre outros motivos, porque ele se tornou uma frase feita para falar das mazelas e das dificuldades da população pobre, substituindo problematizações e distinções que buscam a compreensão da realidade. O conceito aparece incontáveis vezes, de forma naturalizada, em teses,
1 Escola Nacional de Saúde Pública Sergio Arouca, Fundação Oswaldo Cruz, Rio de Janeiro, Brasil.

\section{Correspondência}

M. C. S. Minayo Departamento de Estudos sobre Violência e Saúde Jorge Careli, Escola Nacional de Saúde Pública Sergio Arouca, Fundação Oswaldo Cruz. Av. Brasil 4036, sala 700, Rio de Janeiro, $R J$ 21040-361, Brasil. maminayo@terra.com.br 
dissertações e artigos. Escrever o tal "libelo desconstrutivo" me custou muita reflexão, Naomar, para não dizer muito receio de publicá-lo. Mas caberá ao leitor dizer se ele é um trabalho necessário e se ajuda a repensar categorias naturalizadas. Hoje, no final da minha carreira, não me importa o menosprezo nem a fúria; me valem o debate, a reflexão e o pensamento criativo.

Querido Naomar, eu não confundi determinação, determinantes e determinismo. Ao contrário, eu os conceituei, os distingui e os contrapus ou os integrei, em alguns casos, às possibilidades de usar teorias e metodologias de estudos de temas complexos. Sem apresentar tais conceitos como modelos, mostrei que as suas raízes, que vêm da Biologia, da Física e da Cibernética, são decantadas pelas ciências sociais reflexivas que incluem o sujeito histórico na análise e na compreensão de todas as ações humanas. Tais ciências e as suas teorias são diametralmente opostas à ideia de determinação social. Logo, isso não é uma falácia, é tratar teoricamente e de forma consistente os conceitos e as peças-chave das teorias, porque uns não cabem dentro dos outros ou não nos basta justapor-los. Por exemplo, faz parte da minha limitação intelectual entender onde está o sujeito histórico em Althusser, cuja obra li quase toda. Conforme este filósofo diz, e você, Naomar 5 (p. 2) repete: "a parte contraditória de um sistema é sobredeterminada pelo todo desse sistema, quando as instâncias de determinação são, a um só tempo, determinantes e determinadas, em constante retroalimentação que, por sua vez, reflete uma contradição principal, sendo o todo complexo também produto dessa estrutura". Pergunto: quem é o sujeito histórico? É a estrutura? Ou, na “...acumulação de determinações eficazes saídas das superestruturas e de circunstâncias particulares sobre a determinação em última instância pela economia" 7 (p. 92), o sujeito é a economia? A crítica sociológica do trabalho de Althusser é, principalmente por ter tratado a vida social como um conjunto de estruturas hierarquicamente sobrepostas. O sujeito histórico coletivo ou individual foi substituido por "funções". Gostei mais da frase "o conceito de sobredeterminação estrutura o campo da variação contingente, criticamente contraposto à ideia de "determinação essencial", pensada na perspectiva gramsciana, como um complexo histórico-social de natureza conjuntural e contextual” 5 (p. 2, grifo meu). Fico muito agradecida pela sua leitura e pela sua veemência na contra-argumentação.

Querido Jaime, humildemente aceito as suas críticas, mas não posso concordar com elas. Talvez estejamos trabalhando no mesmo campo, com os mesmos objetivos, mas com instrumentos diferentes. Quero afirmar que concordo com você quando diz que "a saúde é um processo complexo onde não há relações deterministas, mas um movimento entre determinismos e autonomia" 4 (p. 2). Se é assim que você pensa, a sua reflexão coincide com a de muitos outros autores, inclusive a maioria dos que eu cito, para quem isso significa declinar da tese da determinação social, uma expressão muito restrita para representar a dialética entre o que permanece e o que muda tanto na sociedade e no indivíduo como na natureza, seja pela ação humana, pelo acaso ou pelos deslocamentos. Neste tempo de capitalismo exacerbado - ou de hipercapitalismo, como você menciona -, como sempre, são os sujeitos históricos que atuam para o bem e para o mal, não uma força exterior, porque, como dizem os melhores cientistas sociais, todas as estruturas são ações humanas objetivadas.

Reafirmo que não quis destruir o edifício da sua obra intelectual. Apenas me propus a discutir um conceito que, sem explicar, nomeia repetidamente uma visão estática de temas sociais fundamentais, excluindo a historicidade e as múltiplas possibilidades dos seus diferentes atores, inclusive as dos pobres. Acrescento que, quando você me critica por citar autores europeus, minha resposta é que, para mim, o conhecimento não tem pátria, é universal, e por isso não gostaria de cerceá-lo em nenhuma região deste mundo globalizado, cuja economia e política afetam, sim, a todos, porém mais ferozmente os trabalhadores pobres ao redor do planeta. Quando encontro um autor que me ajuda a explicar e a compreender a realidade, eu o leio e o cito, seja a sua obra sobre o populismo que assola a América Latina, o autoritarismo que substitui a democracia, o uso da religião para fustigar as liberdades individuais, as profundas mudanças no mundo do trabalho e a sua desumanização, as imensas transformações trazidas pelas tecnologias de comunicação e informação, o impacto social das novas tecnologias e da biotecnologia, as relações reflexivas promovidas, sobretudo, pelas redes sociais, a descrença nas instituições criadas no e para o mundo industrial, a pobreza e a miséria, o extermínio e o menosprezo pelos indígenas, a destruição da natureza, que tanto afeta nossa saúde, ou a violência social, que persiste e se transfigura de tempos em tempos - atualmente no protagonismo do tráfico internacional de armas e de drogas, só menos lucrativo que o mercado do petróleo. Todos estes problemas não são exclusivos da América Latina, são do mundo, ainda que, claro, precisem ser entendidos em sua especificidade local. 
Querido Jaime, o que me recuso a aceitar é, por exemplo, que os efeitos do colonialismo sejam uma determinação social, que o patriarcalismo conforma uma determinação social, que a discriminação de gênero é uma determinação social ou que a organização da sociedade em classes deriva de determinações sociais. Para mim, tudo isso é a ação humana na História, isto é, na economia, na política e na cultura. É a mesma ação humana que supera os obstáculos, as opressões, as desigualdades e as discriminações contra as quais nós, ativistas sociais, lutamos. Podem me acusar de ir demasiadamente ao concreto, mas foi para torná-lo um "concreto pensado" que escrevi este texto.

\section{Informação adicional}

ORCID: Maria Cecília de Souza Minayo (00000001-6187-9301).
1. Minayo MCS. Determinação social, não! Por quê? Cad Saúde Pública 2021; 37:e00010721.

2. Ianni AMZ. Mudanças sociais contemporâneas e saúde. São Paulo: Hucitec Editora; 2018.

3. Ianni AMZ. Saúde Coletiva e historicidade do conhecimento: teoria, interdisciplinaridade e o sujeito contemporâneo. Cad Saúde Pública 2021; 37:e00227521.

4. Breilh J. La categoría determinación social como herramienta emancipadora. Cad Saúde Píblica 2021; 37:e00237621.

5. Almeida-Filho N. Mais além da determinação social: sobredeterminação, sim! Cad Saúde Pública 2021; 37:e0237521.

6. Minayo MCS. Estrutura e sujeito, determinismo e protagonismo histórico: uma reflexão sobre a práxis da saúde coletiva. Ciênc Saúde Colet 2001; 6:7-19.

7. Althusser L. Contradicción y sobredeterminación (notas para una investigación). In: Althusser L, organizador. La revolución teórica de Marx. Buenos Aires: Siglo XXI; 1967. p. 71-106. 